\title{
A INCOMPATIBILIDADE ENTRE O MITO DA GLOBALIZAÇÃO E O DESENVOLVIMENTO DOS PAÍSES PERIFÉRICOS DIANTE DO SISTEMA DE PODER MUNDIAL*
}

\author{
Cristina Fróes de Borja Reis ${ }^{* *}$
}

\section{Fernanda Graziella Cardoso ${ }^{* * *}$}

\begin{abstract}
RESUMO No artigo proposto, as autoras defendem que o mito da globalização a respeito de um mundo sem fronteiras, com convergência econômica e sem conflitos, é improvável quando se consideram criticamente a própria origem e o funcionamento do impulso globalizante e das relações de poder e riqueza que estão no seio do sistema mundial. Essas relações perpetuam antigas formas de subordinação, as quais aprofundam as contradições do sistema capitalista, destacadamente, a tendência de desigualdade entre classes e nações. Defende-se que é preciso considerar a experiência histórica e as especificidades institucionais, econômicas e políticas dos países para compreender a interação entre os determinantes externos e internos das diferentes trajetórias de desenvolvimento e as suas vias de superação dos efeitos adversos da globalização.
\end{abstract}

Palavras-chave: desenvolvimento; neoliberalismo; dependência

Código JEL: P16, O10

* Artigo enviado em 17 de março de 2008 e aprovado em 2 de agosto de 2010.

** Doutoranda do Instituto de Economia da Universidade Federal do Rio de Janeiro, em estágio de doutoramento na Universidade de Cambridge como bolsista da Capes, e-mail: titi.reis@ie.ufrj.br

*** Doutoranda em Economia das Instituições e do Desenvolvimento - IPE-FEA-USP, e-mail: fernandacardoso@usp.br 


\title{
CONSIDERING THE WORLD POWER SYSTEM, THE MYTH \\ OF GLOBALIZATION AND THE DEVELOPMENT OF PERIPHERAL COUNTRIES ARE INCOMPATIBLE
}

\begin{abstract}
In this article, the authors defend that the myth of the globalization regarding a world without borders, with economic convergence and free of struggles is improbable considering critically the proper origin and the functioning of the globalization's impulse and the relations of power and wealth of the world system. These relations perpetuate old forms of subordination, which make deeper the contradictions of the capitalist system, in particular the trend of inequality between social classes and nations. It is defended that in order to comprehend the different paths of development and surpass of the adverse effects of globalization it is necessary to consider the historical, economic, political and institutional specificities of each country.
\end{abstract}

Key words: development; neoliberalism; dependency 


\section{INTRODUÇÃO}

Diversos trabalhos discutem a globalização e suas implicações sob aspectos diversos. Genericamente, a globalização é aqui tomada como o resultado da multiplicação e da intensificação das relações que se estabelecem entre os agentes econômicos situados nos mais diferentes pontos do espaço mundial (Chesnais, 1996). Muitos autores consideram esse fenômeno positivo, ${ }^{1}$ que em última instância poderia concretizar a perspectiva de que uma boa governança traria a paz perpétua, a convergência econômica e um mundo sem fronteiras entre os países.

Contudo, essa perspectiva é um mito, pois, quando se consideram criticamente a própria origem e o funcionamento do impulso globalizante e das relações de poder e riqueza que estão no seio do sistema mundial, ela mostra-se muito difícil de ser realizada. Essas relações perpetuam antigas formas de subordinação, as quais aprofundam as contradições do sistema capitalista, destacadamente a tendência à desigualdade entre classes e entre nações (Dutt, 2006). Para Fiori,

[o] fenômeno da globalização não é uma imposição tecnológica, nem um fenômeno puramente econômico, envolvendo novas formas de dominação social e política que resultaram de conflitos, estratégia e imposição vitoriosa de determinados interesses, tanto no plano internacional quanto no nacional. E o que é essencial: essas transformações (...) não suprimiram as leis de movimento e tendências de longo prazo do sistema capitalista. (Fiori, 2008, p. 52)

Nesse sentido, com base na experiência histórica e nas especificidades institucionais, políticas e econômicas dos países, no presente trabalho procura-se discutir em que medida os condicionantes internos das nações em vias de desenvolvimento podem estancar e superar o aprofundamento dos efeitos adversos da globalização.

O ponto de partida é uma análise da origem do movimento de internacionalização do capitalismo e do comportamento do hegemon ${ }^{2}$ do sistema mundial. Essa análise está fortemente embasada na teoria de política internacional desenvolvida por José Luis da Costa Fiori. ${ }^{3}$ A pesquisa prossegue com o estudo sobre as alternativas de desenvolvimento dos países periféricos diante do sistema mundial. Pretende-se apresentar a "crucialidade dos condicionantes internos", ${ }^{4}$ fundamentando-se na investigação "histórico- 
-comparativa" 5 empreendida por Ha-Joon Chang em Chutando a escada (2002). Nesse livro, o autor afirma que os países desenvolvidos estariam "chutando a escada" dos países em desenvolvimento, porque as políticas e instituições hoje consideradas imprescindíveis pelo establishment para a promoção do desenvolvimento econômico são, na verdade, exatamente opostas às que os primeiros adotaram para atingir um estágio mais avançado de desenvolvimento.

Assim, o artigo faz uma tentativa de conciliar a perspectiva de Fiori (2007a, 2007b, 2008) sobre o sistema mundial - no qual existem relações claras de poder entre seu principal polo, as demais potências e os integrantes da periferia - e a teoria sobre os condicionantes internos, com o propósito de compreender as alternativas de trajetória de desenvolvimento perante os países que estão em uma condição periférica nas relações de poder e riqueza do sistema mundial.

Além desta introdução, o presente artigo conta com três seções principais. A primeira trata da origem do movimento de internacionalização do capitalismo e descreve o funcionamento do sistema mundial. A segunda seção investiga como as grandes potências "chutam a escada" dos outros países e, com base em uma análise histórico-estrutural, apresenta algumas estratégias de desenvolvimento que poderiam ser tomadas para o avanço econômico, levando em consideração a crucialidade dos condicionantes internos, com destaque para a coalizão social, o papel do estado e das classes dominantes. Finalmente, as conclusões relacionam os principais aspectos abordados no texto.

\section{O SISTEMA MUNDIAL}

Os neomarxistas acreditam que o sistema mundial ${ }^{6}$ moderno baseia-se na competição intercapitalista e na existência de uma hierarquia de poder, sob o comando de um líder, em cada ciclo hegemônico da história. Arrighi (1995) refere-se à liderança hegemônica de um estado como aquela que comanda o sistema de todos os estados "[n] uma direção desejada e, com isso, é percebido como aquele que busca o interesse em geral". ${ }^{7}$ Contrapondo a afirmação de Arrighi, no artigo "Globalização, hegemonia e império", de 1997, Fiori argumenta que o hegemon atua, na verdade, como desestabiliza- 
dor do sistema mundial. Mas deve-se frisar que o conceito de hegemonia não trata de uma gerência funcional ou de uma escolha democrática, mas, ao contrário, de uma posição em disputa e conquista transitória - na qual vence o estado mais poderoso. ${ }^{8}$ Por isso, na visão de Fiori (2004), o anúncio da "morte dos estados" recorrente na literatura após os anos 1990 é, no mínimo, contraditório, uma vez que a competição interestatal e intercapitalista continua mais forte e concentrada, atuando por meio de novos blocos político-econômicos.

A compreensão das relações de poder internacional precisa avançar na tentativa de superar essa inconsistência entre as teorias da hegemonia que preconizam a convergência econômica e a paz - e a prática — que se revela oposta à teoria - , para refletir sobre o desenvolvimento nacional. Assim, as subseções a seguir tratarão da origem e da formação dos Estados Nacionais - subseção 1.1 - e do funcionamento do sistema mundial subseção 1.2 - para que, na seção 2 , se analise como as economias periféricas podem reagir ao jogo de poder internacional no sentido de buscar o desenvolvimento. ${ }^{9}$

\subsection{Origem do sistema mundial baseado em estados nacionais}

Com a intenção de compreender o funcionamento, muitas vezes paradoxal, do sistema mundial, será realizado um recuo no tempo histórico, conforme o método de Fiori (2004, 2007a, 2008), reconstruindo o processo latente de competição e de conflito que culminou na formação dos primeiros estados e economias nacionais, na subsequente expansão de seus poderes e no processo de globalização do capitalismo.

A formação dos estados nacionais pode ser compreendida pelas perspectivas da riqueza e do poder. No que se refere à riqueza, Fiori (2004) afirma que a acumulação primitiva na Europa derivou do comércio de longa distância entre as "economias-mundo", ${ }^{10}$ em que acontecia o "jogo das trocas". Pelo lado do poder, havia os espaços chamados "políticas-mundo", 11 cujas disputas internas formavam o "jogo das guerras". Os estados e o capitalismo europeus nasceram, portanto, no mesmo território - o das "economias-mundo". As guerras tiveram papel fundamental como força expansiva e integradora, sendo o instrumento preferido de acumulação de riqueza e poder. Elas obrigaram a estruturação interna do território e dese- 
nharam suas fronteiras, também requeridas pelo jogo das trocas. A guerra mais importante para o nascimento dos estados nacionais foi a Guerra dos Cem Anos (1337-1453), quando a França e a Inglaterra formaram suas identidades nacionais. Mas foi ao final da Guerra dos Trinta Anos (16181648), com o acordo denominado "Paz de Westfália", que se originou o "sistema político europeu". 12

A importância das guerras foi investigada, por exemplo, por Tilly e Elias. Tilly (1996) argumenta que a as guerras acontecem porque "[a]queles que aplicam força substancial sobre seus camaradas obtêm condescendência, e dessa condescendência tiram múltiplas vantagens". ${ }^{13}$ A guerra é a causa da expansão territorial, conforme afirma Elias (1993). Analisando o comportamento dos estados, em que pese o seu contexto no sistema mundial, Elias afirma que a guerra é condição básica de sobrevivência das unidades imperiais, pois “[a] mera preservação da existência social exige, na livre competição, uma expansão constante. Quem não sobe, cai”. ${ }^{14}$ Várias unidades de poder em concorrência partem para a guerra porque não querem ser aglutinadas por uma unidade mais poderosa do que elas. Na medida em que as guerras geram vencedores e vencidos, as unidades de poder vão diminuindo; daí a conclusão usual de que a tendência é sobrar uma única unidade social monopolizadora.

Fiori (2004) faz uma importante observação sobre o movimento de concentração e centralização de poder a partir das guerras: este não seria nem linear, nem irreversível. Sem embargo, as dimensões e os custos das guerras cresceram de forma exponencial. Por isso, a convergência entre o mundo da guerra e o mundo dos negócios se aprofundou de maneira crescente, de tal modo que a própria guerra, do ponto de vista econômico, se transformou em um grande negócio — as chamadas "máquinas de guerra”.

Contudo, tornar-se um único imperium não é interessante para o estado hegemônico, porque acabaria com o processo de acumulação de poder, o que significaria a entropia do imperium, pois o jogo que gera processo de acumulação pressupõe a existência de adversários. Portanto, o estabilizador do sistema mundial não é o hegemon. A competição e a guerra - ou a possibilidade de guerra - é que são os estabilizadores. Segundo afirma Fiori (2004, p. 18), "[e]ste talvez seja o segredo mais bem guardado deste sistema: o próprio 'poder expansivo' é quem cria ou inventa, em última instância, os 
seus competidores e adversários, indispensáveis para a sua própria acumulação de poder”.

A introdução da moeda estatal, de acordo com Elias (1993), foi muito importante, pois permitiu a centralização dos monopólios de poder, outrora muito segmentados. $\mathrm{O}$ autor afirma que o uso progressivo da moeda possibilitou ao processo formador de monopólios de dominação "[a] forma combinada de centralização dos impostos e de controle de todos os instrumentos que serviam à subjugação física". ${ }^{15}$ Quanto mais recursos o poder central dispõe para guerrear, maior a probabilidade de vitória e, consequentemente, de aquisição de mais poder e riqueza. A dívida pública e a aliança entre os chefes de estado e o sistema financeiro tornam-se, então, essenciais armas de guerra. Como bem destaca Fiori, o encontro entre os proprietários do dinheiro e os proprietários do poder é a origem real do capitalismo, junto com os lucros extraordinários da guerra, "[p] or cima da economia de mercado onde se produzem e acumulam os "lucros normais". ${ }^{16} \mathrm{O}$ incremento inicial do sistema capitalista se dá por meio da mais-valia política, que é a capacidade do poder de se multiplicar, usando a (preparação da) guerra como via principal. Nesse caso, a palavra preparação faz toda a diferença, porque se a ameaça de guerra for suficiente para a expansão do poder, não haverá grande perda de recursos relativamente ao que aconteceria se a guerra se consumasse. A partir da constituição das “economias-estados nacionais", iniciou-se o movimento de internacionalização do capital. Essas unidades de poder e riqueza possuíam moeda, exército e identidade próprios. Além disso, a dívida pública e o sistema de crédito eram nacionalizados. Uma vez colocadas a homogeneização interna dos estados nacionais ${ }^{17}$ e a necessidade de expandir sua acumulação de poder e, por conseguinte, de riqueza, surge o impulso internacionalizante do capital.

Tomando-se o sistema mundial como parte de um "universo" que se expande de forma contínua, a partir do "longo século XIII", ${ }^{18}$ Fiori (2008) propõe a identificação de quatro momentos de "explosão expansiva", nos quais houve, inicialmente, um aumento da "pressão competitiva" — provocado pela expansão e o conflito entre potências líderes - dentro do "universo", e depois uma grande "explosão" ou alargamento das suas fronteiras internas e externas.

No primeiro momento, entre 1150 e 1350, o aumento da "pressão competitiva" dentro da Europa se originou nas invasões mongóis, nas Cruzadas 
e nos conflitos na Península Ibérica, no norte da França e na Itália. O segundo momento foi no "longo século XVI" (expressão de Ferdinand Braudel), entre 1450 e 1650, provocado pelo expansionismo do Império Otomano e do Império Habsburgo e pelas guerras da Espanha, com a França, com os Países Baixos e com a Inglaterra. Nascem os primeiros estados europeus, com suas economias e capacidade bélica nacionais, ou seja, origina-se o "sistema mundial moderno", ${ }^{19}$ liderado, inicialmente, pelas potências ibéricas, e depois pela Holanda, França e Inglaterra. O momento seguinte foi entre 1790 e 1914, com o expansionismo francês e inglês, a independência dos estados americanos e a ascensão de três potências: Estados Unidos, Alemanha e Japão. Esses estados se expandiram de forma muito veloz, revolucionando o "núcleo central" das grandes potências. E, desde a década de 1970, está em curso uma quarta "explosão expansiva" do sistema mundial, provocada pela estratégia expansionista e imperial dos Estados Unidos, pela multiplicação dos estados soberanos do sistema e pelo crescimento vertiginoso do poder e da riqueza dos estados asiáticos, a China em particular (Fiori, 2008).

Em resumo, desde a formação dos estados, sempre existiu um conflito central, que serve como eixo organizador do sistema. Nesse eixo central, há períodos de contraposição ou de complementaridade e há, também, uma polaridade que funciona como uma "negarquia" e impede o uso abusivo do poder. ${ }^{20} \mathrm{~A}$ armação do eixo central do sistema mundial será mais bem desenvolvida na subseção a seguir.

\subsection{Funcionamento do Sistema Mundial}

Uma vez constituídos os estados-economias nacionais e postas as competições política e econômica entre eles, vem à tona o paradoxo de que, se a destruição dos adversários for efetuada, não haverá mais meios para continuar nem o processo de acumulação de poder, nem o de riqueza. Retomando a observação de Hilferding (1985), de que o capital financeiro tem um tríplice objetivo - a criação de um território econômico o mais vasto possível, a defesa de tal território por meio de barreiras aduaneiras e a sua transformação em campo de exploração para os monopólios do país - , Fiori (2004) destaca que, do ponto de vista capitalista, o essencial é a conquista permanente de novas posições monopólicas e, por definição, capazes de gerar lucros extraordinários. E, para conquistar tais posições, é necessá- 
rio agir de maneira constantemente inovadora, já que só a partir de tal ação é possível construir situações monopolistas - mesmo que temporárias. Baseando-se em tal ideia, a globalização capitalista é " [u]m movimento expansivo e uma resultante transitória do processo de competição entre as Grandes Potências e seus capitais financeiros, pela conquista de novos 'territórios econômicos". 21

O núcleo do sistema interestatal formado pelas grandes potências sempre foi reduzido e com barreiras à entrada bem estabelecidas, e, além disso, tal grupo apresentou uma composição relativamente estável no decorrer dos séculos. A partir do século XIX, o problema da concentração de poder teria se tornado ainda mais evidente, com o grande aumento observado da formação dos novos estados nacionais, formados fundamentalmente de ex-colônias que, em geral, se conformaram à periferia do sistema mundial.

Assim, desde o século XX, o sistema mundial possui um caráter hierarquizado e polarizado. Podemos dizer que a forma de colonização não é mais territorial e, sim, através da superioridade político-econômica e da força do capital financeiro do eixo central de poder. O problema das grandes potências, nesse contexto, é manter-se no poder, enquanto o dos países da periferia é afirmar a própria soberania. De acordo com Wallerstein (2004), a soberania é uma alegação e, portanto, possui pouco significado se não for reconhecida pelos outros: "A soberania é mais do que qualquer outra coisa uma questão de legitimidade". ${ }^{22}$

Fiori (1997) apresenta quais são os limites da resistência contra a expansão do capital das nações mais poderosas. O primeiro deles, de natureza econômica, é o de que a acumulação da economia capitalista depende da competição interestatal. O segundo, de natureza ética e política, é que a "ausência de outros poderes e de uma capacidade efetiva de veto não conduz na direção de uma soberania absoluta e benevolente (...), mas à arbitrariedade e ao fascismo em última instância". ${ }^{23} \mathrm{O}$ terceiro limite é o de que uma ordem política e econômica se mantém a longo prazo apenas se o estado hegemon mantiver sua legitimidade perante os governados.

No sistema mundial existem alguns estados periféricos que nunca chegarão a ser potências, e, por sua vez, existem também "países ricos que não são, nem nunca serão, potências expansivas, nem farão parte do jogo competiti- 
vo das Grandes Potências". ${ }^{24}$ Esses estados não têm soberania real e não conseguem formar, autonomamente, a identidade nacional, moeda "forte" e sistema de dívida pública necessários para possibilitar a expansão da acumulação de capital e poder. Fiori (2007a) afirma que os demais estados nacionais, oriundos da decomposição dos impérios das grandes potências, sempre tiveram menor soberania do que os do núcleo central.

Ao final do século XX, enquanto se processava um "novo ciclo de aceleração do processo permanente de internacionalização capitalista", ${ }^{25}$ se reconstruíram-se as hierarquias geopolíticas e geoeconômicas. Mas a reconstrução não é um processo automático e ocorre de forma diversa na periferia do sistema, notadamente entre os países da Ásia, África e América Latina, de acordo com as estratégias regionais e globais de cada um. Resumidamente, podemos afirmar que boa parte dos asiáticos, por meio de políticas que por uma ou outra característica diferiram daquelas recomendadas pelos países do centro, galgou à condição de desenvolvimento. No caso de boa parte dos latino-americanos, que por muito tempo se mantiveram na liderança da periferia, eles abandonaram sistematicamente as políticas desenvolvimentistas adotadas até então e, ao contrário dos asiáticos, destacadamente do Sudeste, não superaram a sua condição de subdesenvolvimento (Medeiros, 1997). Por fim, no caso africano, o que se observou nessa fase foi inclusive um retrocesso econômico em grande parte dos países. ${ }^{26}$

Com a consolidação da hegemonia liberal-conservadora no mundo capitalista, após o fim da guerra fria, as redes de poder integradas em uma esfera supranacional passaram a preocupar-se principalmente com a administração macroeconômica global. Na periferia, a internacionalização dos centros de decisão macroeconômica foi mais direta. Essa internacionalização da macroeconomia liberal-conservadora é também um ato de vontade política interna de cada país. Esse ato gera uma "lenta e progressiva erosão da soberania interna (...) que pode ameaçar, de fato, a sobrevivência desses estados nacionais". ${ }^{27}$ No entanto, historicamente, alguns países como a Alemanha, o Japão e os Estados Unidos conseguiram sair da periferia do sistema. Na próxima seção, a revisão histórica do desenvolvimento dos países avançados de Chang (2002) demonstra que estes não teriam alcançado tal condição se tivessem adotado desde sempre as políticas e instituições que hoje recomendam. 


\section{0 "Chute DA escadA" e O Desenvolvimento}

Discutidas a origem e a formação dos estados nacionais, nesta seção busca-se analisar as possibilidades de reação - no sentido de buscar o desenvolvimento - das economias periféricas, dado o contexto do jogo de poder internacional. Inicia-se com uma breve discussão metodológica, contrapondo as abordagens neoclássica e histórico-estruturalista - subseção 2.1. Na subseção seguinte, 2.2, retomamos a discussão de sistema mundial destrinchada na seção 1, avançando-a na direção das possibilidades de desenvolvimento dos países periféricos. Por fim, na subseção 2.3, com base em Chang (2002), discutimos em que sentido os países periféricos têm sofrido o chute da escada do desenvolvimento.

\subsection{Breve discussão metodológica: uma contraposição entre a abordagem neoclássica e a histórico-estruturalista}

A noção de desenvolvimento econômico está relacionada, em cada abordagem teórica, à definição de estado. A visão neoclássica geralmente aborda o tema por meio de teorias de crescimento do longo prazo, considerando um ou mais dos seguintes pressupostos: pleno emprego, plena substituição entre os fatores capital e trabalho, equilíbrio endógeno no mercado de trabalho, maximização de preferências individuais e expectativas racionais, inexistência de incerteza e informação e tecnologia simétrica. ${ }^{28}$ Essas premissas estão presentes nos textos que adotam uma visão de crescimento exógeno, como Solow (2000), e endógeno, como os de capital humano de Mankiw (1995) e Lucas e Frenkel apud Serrano (2001). Valem também para os modelos de trocas em economia aberta de vantagens comparativas do tipo Hecksher-Ohlin-Samuelon. Ou seja, esses modelos são de equilíbrio geral, em sua maioria estáticos, e concluem que o desenvolvimento capitalista, se conduzido pelos livres-mercados, com mínima intervenção estatal, com boas instituições e devidamente regulados, é um processo natural que leva à convergência de padrões de vida entre os países.

Contudo, uma série de críticas pode ser levantada contra essa abordagem. Em primeiro lugar, as premissas que marcam o individualismo metodológico da visão neoclássica para o estudo do desenvolvimento fazem com que este seja um resultado de conquistas individuais relacionadas à educação, saúde, instituições sociais, microfinanças e direitos de propriedade. ${ }^{29}$ 
Em segundo lugar, as premissas e o modelo de equilíbrio geral defendem que os mercados devam operar livremente ${ }^{30}$ e o papel do Estado deva ser limitado, à revelia do que se observou na história do mundo. ${ }^{31}$ Em terceiro lugar, várias premissas neoclássicas não são a regra na economia — destacadamente a de retornos marginais decrescentes para a acumulação de capital —, portanto, suas implicações de curto e longo prazo são fictícias. ${ }^{32}$ Em quarto lugar, as teorias neoliberais desconsideram o sistema capitalista interestatal e suas relações de poder e riqueza.

Alternativamente, a forma de análise "histórico-estruturalista" focaliza o objeto de estudo a partir do ponto de vista da produção para sugerir que as diferentes vias de desenvolvimento são parcialmente influenciadas pelas condições materiais, mas também pela dinâmica produtiva, políticas do estado e relações econômicas, sociais e políticas internacionais. Rodriguez (2009) afirma que o método estruturalista é evolutivo, possui caráter científico e de "revisão dos graves problemas atuais da área (economia) e de busca e desenho de soluções condizentes" (2009, p. 23). Pode-se defini-lo como um método que enfoca a estrutura econômica, considerando sua formação e transformações - e por isso ele é necessariamente, concomitantemente, histórico. Segundo o autor, esse método possui uma implicação natural vantajosa de não ser reducionista, tanto em relação à economia quanto aos aspectos institucionais, sociais e políticos. Além disso, nesse método não se adota uma visão mecanicista do comportamento maximizador dos agentes e o papel do estado é crucial para entender o desenvolvimento. Consequentemente, o método é não determinista, pois associa desenvolvimento a uma série de fatores e "legitima a busca de alternativas para os processos globais de desenvolvimento que contemplem a compatibilidade dos elementos mencionados e, com ela, a continuidade de tais processos nos marcos da(s) alternativa(s) escolhida(s)" (2009, p. 48).

Nessa abordagem, as economias de mercado não tendem ao pleno emprego da mão de obra e nem à plena utilização do capital. O desenvolvimento se refere à formação completa da estrutura produtiva da economia e à ocupação de mão de obra entre os diferentes tipos de atividade econômica, ao aumento da produtividade agrícola e industrial, ao aumento do nível médio de salários, à capacidade de gerar e/ou adaptar-se às mudanças estruturais tecnológicas, à melhoria do nível de vida da sociedade median- 
te o acesso a serviços básicos como saneamento, moradia e transporte, à oferta de infraestrutura (transportes, comunicação e energia), às coalizões de poder dentro dos estados, às questões de relações e hierarquia de poder interestatal dentro do sistema internacional. ${ }^{33}$ No caso dos países periféricos, o desenvolvimento envolve necessariamente a mobilização e a organização dos recursos e aptidões necessários para formar um sistema produtivo que supere as diferenças tecnológicas e de produtividade. Assim, a transformação social e econômica dos países atrasados requer um estado capaz de formular e implementar políticas estatais que propiciem o desenvolvimento.

\subsection{O desenvolvimento dos países periféricos diante do sistema de poder mundial}

A Inglaterra tornou-se o hegemon do sistema mundial a partir do século XVII por meio, pelo lado do poder, de uma estratégia de ataque bélico-militar e, pelo lado da riqueza, de uma política mercantilista iniciada com os Atos da Navegação de Cromwell, em 1651. Nas palavras de Weber (1950), "[a] Inglaterra é distintivamente o lar original do Mercantilismo". ${ }^{34}$ Subordinados a ela e às outras grandes potências estavam os estados periféricos que não conseguiram formar, autonomamente, a identidade nacional, moeda "forte" e sistema de dívida pública necessários para possibilitar a expansão da acumulação de capital e poder. A excessiva dependência histórica de capital externo possibilitou a união entre os interesses expansionistas das potências hegemônicas com os grupos de interesses dominantes da periferia. Em geral, os grupos dominantes de tais países não tinham um projeto nacional industrializante que culminasse em bases sólidas de desenvolvimento econômico.

Segundo Reis e Cardoso (2009a, 2009b), a relação que a Inglaterra estabeleceu com as nações periféricas sempre manteve uma tensão política que não resultasse em ameaça ao seu poder. Dessa forma, tanto a relação de "desenvolvimento a convite" travada com seus domínios formais - e com a Argentina, até certo grau —, quanto as relações mais exploratórias, como a desenrolada com o Brasil, mantiveram a resiliência necessária para que a Inglaterra prosseguisse acumulando poder e riqueza. Assim, como argumenta Fiori: 
No núcleo orgânico dessa ordem mundial, a complementaridade foi companheira inseparável da competição tanto no campo econômico como no político, enquanto dentro dos espaços inferiores do imperium europeu houve apenas casos de complementaridade econômica ou de submissão e extração pura e simples da riqueza disponível. (...) A Inglaterra, secundada por este núcleo orgânico, determinou os ritmos cíclicos da economia (...). Suas consequências, entretanto, variaram enormemente, dependendo não apenas das condições naturais e demográficas, mas também das relações políticas que se estabeleceram com os três estamentos básicos da periferia: as colônias, os dominions e os países independentes. (Fiori, 1999, p. 65)

"Conforme Fiori (2004) descreve, os modelos de desenvolvimento capitalista no século XIX, sob hegemonia da Inglaterra, das "colônias brancas" - como Estados Unidos, Canadá e Austrália (Reis e Cardoso, 2009a) — e dos países periféricos independentes que se especializaram e promoveram a integração liberal — como os latino-americanos (Reis e Cardoso, 2009b) — não possibilitaram que nenhum desses dois grupos de países fizesse parte do eixo central de poder do sistema mundial. Portanto, a relação que tais países estabeleciam com a Inglaterra seria um fator criador de diferenças. Os países que fizeram catch up por meio de políticas mercantilistas/nacionalistas, como os Estados Unidos, a Alemanha e o Japão, conseguiram isso porque seus projetos nacionais eram expansionistas e existia uma relação de complementaridade virtuosa acumulativa com o hegemon".

Tendo em vista o argumento de Lewis (1954) — de que a Revolução Industrial inglesa desafiou os outros países no século XIX a fazerem o catch up econômico e tecnológico por meio ou da imitação ou do comércio circunstâncias políticas e econômicas externas e internas permitem entender por que muitos países se inseriram no comércio internacional como exportadores de bens primários e por que não usaram o excedente (caso tenha existido) para se desenvolverem.

Nesse sentido, também Gilpin (1987) considera que as evidências sugerem que o comércio mundial agrava ou neutraliza conflitos, conforme forem as circunstâncias políticas. Algumas consequências políticas do comércio são a existência ou ausência de um poder dominante ou hegemônico que administra o sistema de comércio internacional; a taxa de crescimento econômico desse sistema e o grau de homogeneidade da estrutura industrial, que, por sua vez, determinaria a composição e distribuição das impor- 
tações e das exportações. O autor afirma também que, em geral, o caráter das relações internacionais depende das configurações de poder e de interesses estratégicos entre os maiores e menores poderes do sistema. Por exemplo, as condições naturais determinaram a produção na periferia de produtos de agricultura temperada ou de agricultura tropical, o que por si só já estabeleceria diferenças significativas entre esses países.

\subsection{0 chute da escada do desenvolvimento}

Chang (2002) sugere que os países desenvolvidos teriam "chutado a escada" dos países periféricos durante toda a história, impedindo-os de se desenvolverem, especialmente via recomendação de instituições e políticas que considerariam mais adequadas. Embasando o argumento do autor está uma investigação histórica detalhada de estratégias de catch up bem-sucedidas, como as da própria Inglaterra, Estados Unidos, Alemanha e Japão, dentre outros. No caso inglês, vale destacar que, segundo o autor, a supremacia tecnológica que viabilizou a posterior guinada para o regime de livre-comércio teria sido possibilitada por um longo período de elevadas barreiras tarifárias. Com relação à experiência dos Estados Unidos, vale destacar que a proteção tarifária foi crucial para o desenvolvimento de certas indústrias-chave. Já no caso alemão, parece ter sido de fundamental importância a intervenção direta do estado nas indústrias-chave. Por fim, no caso japonês, o envolvimento do estado não teria se restringido apenas à implantação de fábricas modelos, mas também teria atuado no desenvolvimento infraestrutural, além de ter lançado mão de forte proteção a algumas indústrias-chave.

Após discutir a experiência de países que concluíram o processo de catch up, Chang deriva o que chama de lições para o presente, especialmente para serem consideradas pelos países periféricos, uma vez que "o fato patente é que as 'reformas políticas' neoliberais se mostraram incapazes de cumprir a sua grande promessa: o crescimento econômico" (Chang, 2002, p. 212). Segundo o autor, a tarefa de melhorar a qualidade das instituições é crucial para aqueles países em desenvolvimento que pretendem acelerar o crescimento econômico e o progresso. No entanto, enfatiza que há de se observar que o processo de aprimoramento institucional é demorado, e por isso deve ser feito pacientemente. Ademais, para o autor, as instituições ade- 
quadas só produzem bons resultados quando associadas a políticas igualmente adequadas:

[O] fato é que, apesar da contínua e presumível aceleração do aperfeiçoamento de suas instituições nas últimas duas décadas, os países hoje em desenvolvimento têm experimentado acentuadas desacelerações no crescimento (...). Na minha opinião, isso se deve a que a sua capacidade de recorrer às políticas (genuinamente) boas foi significativamente reduzida em razão das "reformas políticas" implementadas no período. (Chang, 2002, p. 220)

Desse modo, um exemplo atual de "chute da escada" é justamente o de que, nos anos 1990, se recomendou aos países atrasados que promovessem a abertura e a desregulamentação de suas economias por meio de reformas de cunho neoliberal, reformas essas distintas das políticas intervencionistas adotadas pelos países avançados durante a sua transição para o desenvolvimento. $\mathrm{O}$ ideal de que necessariamente haverá convergência se forem adotadas as políticas e instituições consideradas imprescindíveis pelo establishment para a promoção do desenvolvimento econômico funciona como justificativa para a constante pressão que os países avançados realizam sobre os países em desenvolvimento para que se adaptem aos padrões mundiais estabelecidos pelos países do centro.

Partindo do fato de que na verdade o que tem se verificado como regra é a divergência entre os níveis de desenvolvimento econômico dos países já avançados e dos países ainda em desenvolvimento, propõe-se uma breve discussão da importância da adequação das políticas e instituições às especificidades de cada país para que a estratégia de desenvolvimento tenha ao menos possibilidades de ser bem-sucedida.

Em geral, é tomado como ponto pacífico que as políticas e instituições consideradas como adequadas foram de fato adotadas pelos países hoje avançados quando estavam ainda em vias de desenvolvimento. Entretanto, segundo Chang, as políticas e instituições tão recomendadas hoje aos países em desenvolvimento não foram de fato empregadas pelos países desenvolvidos quando estavam em processo de catching up. Uma revisão histórica do desenvolvimento dos países avançados permitiria concluir que estes não teriam alcançado tal condição se tivessem adotado desde sempre as políticas e instituições hoje consideradas adequadas. 
Nas últimas décadas, as áreas de pesquisa de economia do desenvolvimento e de história econômica, consideradas aqui como cruciais para a discussão da temática e do desenvolvimento do subdesenvolvimento, teriam sido subjugadas pela predominância da teoria neoclássica, que não concede nenhuma relevância à perspectiva histórica, e justamente é a que baseia as políticas de desenvolvimento recomendadas do centro para a periferia.

Nesse sentido, Chang argumenta que a atual política ortodoxa recomendada faz o possível para "chutar a escada", pois impedir que as nações ainda em processo de desenvolvimento adotem políticas industrial, comercial e tecnológica diferenciadas constitui uma séria limitação ao seu desenvolvimento econômico. Com relação às instituições, o autor ainda sugere que muitas daquelas consideradas imprescindíveis para o processo de catch up são mais consequência do que causa do desenvolvimento econômico. E também não estaria claro quais dessas instituições consideradas imprescindíveis pelo establishment são mesmo necessárias aos países em desenvolvimento, se é que realmente alguma delas o seja de fato. Ainda que alguma dessas instituições seja julgada necessária, é preciso cautela nas suas especificações. Todavia, adverte o autor, o fato de que muitas das instituições atualmente recomendadas não sejam necessárias ou benéficas não implica que as instituições não sejam importantes ou que os países em desenvolvimento não precisem aperfeiçoar as suas.

A efetivação dos condicionantes internos mais importantes para o desenvolvimento perpassa pela existência de um estado sustentado por uma coalizão política interessada em promover um projeto nacional industrializante. Historicamente, a transição da maioria dos países industrializados avançados ${ }^{35}$ contou com uma ação dos estados no sentido da proteção à indústria infante, cooperação regional, dinamismo municipal, diminuição do coeficiente de importações, aperfeiçoamento da educação para a elevação da produtividade em geral e expansão do mercado interno, com melhor distribuição de renda. E, ainda, as políticas governamentais valeram-se de barreiras tarifárias, investimento em infraestrutura, apoio à pesquisa e ao desenvolvimento. ${ }^{36}$

É fundamental, então, enfatizar e compreender a importância da coalizão social a favor de um projeto de desenvolvimento econômico, a qual, defende-se, trata-se de um condicionante interno fundamental para que um projeto 
nacional possa ser bem-sucedido. Afinal, “[p]ara compreender adequadamente os resultados obtidos por tais países - e, por conseguinte, a situação em que se encontram atualmente - é necessária a investigação tanto dos condicionantes externos quanto internos" ${ }^{37}$ Ademais, vale destacar "[a] crucialidade da postura das diversas classes sociais, principalmente da elite dominante, na determinação da natureza do desenvolvimento socioeconômico" ${ }^{38}$

Em que se pese essa perspectiva, pode-se, então, pensar nas trajetórias recentes das economias nacionais. Por exemplo, Medeiros (1997) argumenta que as transformações ocorridas a partir dos anos 1980 se refletiram de maneira diferenciada na Ásia e na América Latina. Na Ásia, a participação mais direta do estado na economia seria um dos fatores principais para entender a recuperação da Coreia no pós-guerra e da China a partir das reformas de 1979, articulando o modelo de inserção externa baseada em manufaturas com o desenvolvimento do mercado interno via aumento de produtividade, mudança da estrutura industrial, capacitação e investimento em pesquisa e tecnologia. No que se refere à economia latino-americana, sua inserção externa agrário-exportadora se deu como receptora de fluxos financeiros de curto prazo e como mercado em expansão para os Estados Unidos. E tal inserção teve como consequência uma maior fragilidade externa relativamente aos asiáticos nos anos 1990. Ainda segundo Medeiros, os vínculos entre a taxa de juros e a taxa de câmbio provocaram uma significativa instabilidade em ambas, ampliando ainda mais a subordinação da política econômica latino-americana aos movimentos dos mercados financeiros internacionais. Quanto à explicação para tal fragilidade, o autor a atribui a fatores geopolíticos, macroeconômicos, microeconômicos e institucionais.

Também discutindo o caso latino-americano, Palma (2003) indica que, apesar de o processo de substituição de importações — PSI — adotado pela América Latina no pós-guerra ter levado a um grande crescimento na indústria, o fez associado a políticas e capitais de curto prazo, o que posteriormente levou aos constrangimentos sobre o investimento, à menor utilização da capacidade produtiva, aos ciclos de stop-and-go e aos empréstimos externos excessivos. O autor argumenta, então, que, paradoxalmente, a história teria se repetido recentemente, e conclui que uma explicação realista para o desempenho e a inserção latino-americanos é que, mesmo quando as políticas mudam, na verdade é para que tudo continue a ser como sempre foi. 
Ou seja, a atuação político-econômica dos estados nessa região sempre garantiu que o "sonho das elites" 39 perdurasse, atuando para sustentar sua posição e sua renda desproporcionalmente superior à das outras classes, sem enfrentar a dramática questão da desigualdade social.

Antes de encerrar, vale destacar também a discussão feita por Kotz (2004) com relação à natureza e à eficácia das estratégias. $\mathrm{O}$ autor argumenta que tanto para uma transição econômica quanto para o desenvolvimento econômico, uma estratégia de transformação direcionada pelo estado é superior à estratégia neoliberal, deixada à livre ação das forças dos mercados, embora o autor advirta que o papel do estado na economia por si só não garante o sucesso econômico, seja no desenvolvimento ou na transição. No entanto, a adoção da estratégia neoliberal seria ainda mais propensa à falha: na questão do desenvolvimento econômico, a falha da estratégia neoliberal tenderia a produzir estagnação; no caso da transição, a consequência de aderir à estratégia neoliberal poderia levar a um rápido movimento para trás, com colapsos econômicos e sociais nos piores casos.

\section{CONCLUSÕES}

Buscou-se demonstrar neste artigo que a retórica neoliberal não vale para compreender o sistema mundial e o processo de desenvolvimento dos países atrasados, em que pese o funcionamento do sistema capitalista internacional. A convergência da riqueza relativa das nações - o fim lógico dessas teorias - não é factível, pois a competição e a (possibilidade de) guerra são os estabilizadores do sistema mundial. A acumulação de poder e riqueza por parte do poder expansivo precisa de adversários e da possibilidade de ataque. O sistema globalizante é essencialmente desigual, porque a expansão das unidades capitalistas necessita de outras unidades ricas e poderosas, mas renova as desigualdades.

O respeito e a manutenção de regras estáveis defendidos por institucionalistas empacam a acumulação de riqueza, pois é justamente a sua transgressão que gera oportunidades de lucros extraordinários. E, a despeito do que acreditam os liberais, o desenvolvimento das "economias-mundo" foi possível somente mediante práticas intervencionistas. O liberalismo é o discurso apenas dos vitoriosos, conforme o próprio Adam Smith já havia deixado claro na obra A riqueza das nações. 
A partir da confirmação de que o processo de convergência do desenvolvimento econômico dos diversos países e regiões é um mito, e da interessante sugestão de Chang de que ao recomendarem as ditas políticas e instituições supostamente adequadas os países avançados estão na verdade "chutando a escada", impedindo que os países ainda em processo de desenvolvimento também cheguem ao "topo", o presente trabalho enfatizou que, para ao menos haver chances de uma estratégia de desenvolvimento ser bem-sucedida, as especificidades econômicas, sociais e culturais dos países devem ser levadas em conta.

Para a definição de quais são as estratégias, bem como as políticas e instituições mais adequadas para cada país, é crucial que se façam investigações históricas sérias, tanto com o intuito de aprender com experiências já realizadas quanto para incrementar o grau de complexidade e, por conseguinte, as chances de sucesso das estratégias de desenvolvimento econômico. E, ainda mais importante, o estado tem um papel fundamental para promover o desenvolvimento de um país. Portanto, o tipo de coalizão política interna de cada país tem grande peso na determinação da trajetória de desenvolvimento a se trilhar.

\section{NOTAS}

1. Vide por exemplo, Friedman (2005), Nye e Keohane (1997).

2. O conceito de hegemonia não se trata de uma "gerência funcional" ou de uma "escolha democrática”; trata-se, ao contrário, de uma posição em disputa e conquista transitória — na qual vence o estado mais poderoso.

3. Fiori (1997, 1999, 2004, 2007a, 2007b, 2008).

4. Reis e Cardoso (2009a, 2009b).

5. Esse método será discutido mais profundamente na seção 2.

6. Para Wallerstein (2004), o world-system trata-se de uma zona espacial/temporal que recorta muitas unidades políticas e culturais e obedece a certas regras sistêmicas. O hífen serve para lembrar que os termos não se referem a sistemas, economias e impérios do mundo, mas, sim, a sistemas, economias e impérios que são o mundo.

7. Arrighi, 1995, p. 29.

8. Fiori, 2004, p. 53.

9. O presente trabalho concede papel central e necessário à industrialização para que se configure de fato o desenvolvimento econômico. O desenvolvimento econômico é um processo de mudança estrutural que permite elevar a produtividade do conjunto da 
economia mediante a acumulação de capital, sustentando altas taxas de crescimento a médio e longo prazos. Por mudança estrutural entende-se a mudança dos coeficientes técnicos das funções de produção e da matriz insumo-produto de um país (Reis, 2008).

10. Fiori (2004) denomina "economias-mundo", com base na definição de Ferdinand Braudel, os territórios com comércio intenso que reuniam um conjunto hierarquizado de vilas, com moeda privada e articulado por uma liderança.

11. Fiori (2004) denomina "políticas-mundo" os territórios integrados e unificados por conflitos permanentes, onde um polo obtém mais poder através da guerra.

12. Elias diz que após a Guerra dos Cem Anos surgiu o "primeiro sinal daquilo que emergiria com nitidez maior" após a Guerra dos Trinta Anos: o continente europeu tornara-se um sistema interdependente de países com sistema dinâmico próprio (Elias, 1993, p. 129).

13. Tilly, 1996, p. 127.

14. Elias, 1993, p. 134.

15. Elias, 1993, p. 135.

16. Fiori, 2004, p. 31.

17. Identidade nacional, exército, moeda, dívida pública e sistema de crédito.

18. Conforme explica Fiori (2008), essa expressão foi utilizada por Peter Spufford para referir-se ao período da história europeia, entre 1150 e 1350, em uma analogia ao "longo século XVI" de F. Braudel.

19. Fiori (2004) esclarece que esse conceito clássico de Immanuel Wallerstein é utilizado por ele sem a mesma conotação teórica do autor, apenas com a mesma referência cronológica.

20. Fiori (2004).

21. Fiori, 2004, p. 45.

22. Wallerstein, 2004, p. 44.

23. Fiori, 1997, p. 131.

24. Fiori, 2004, p. 49.

25. Fiori, 2008, p. 78.

26. De acordo com cálculos a partir de Historical statistics of the world economy, de Angus Maddison (2006), de 1970 a 2006 o Sudeste Asiático teve um crescimento médio anual da renda per capita um pouco superior a 3\%, enquanto o da América Latina foi inferior a $1,5 \%$ e o da África total, $0,7 \%$.

27. Fiori, 1997, p. 140.

28. Classificação com base em Serrano (2001), Possas (1987) e Medeiros e Serrano (2001).

29. Chang (2009).

30. Paulani (2004, p. 5-6) critica as teorias neoliberais por serem normativas (o mercado deve dominar tudo, e o estado deve ficar reduzido ao papel de preservar as instituições que permitam o funcionamento do primeiro) e prescritivas (pois arrolam medidas que 
devem ser tomadas para que seja construído o mundo completamente organizado pelo mercado). Diz a autora: "Não há papel aí, portanto, para a 'ciência' econômica. A norma que define essa doutrina não decorre da constatação 'científica' (que seria em princípio produzida pelo paradigma neoclássico) de que essa sociedade é a melhor possível e/ou de que o mercado é o demiurgo de um processo que maximiza utilidades e lucros e minimiza custos, produzindo o 'ótimo social."

31. Chang (2002).

32. Segundo Cesaratto e Serrano (2002, p. 2), "a teoria neoclássica da distribuição e da utilização de fatores requer retornos marginais decrescentes para a acumulação de capital (e, em geral, para o uso de qualquer fator). Os retornos marginais decrescentes para a acumulação de capital estão por trás da insatisfação de muitos com o modelo de crescimento exógeno como o de Solow, pois tornam a taxa de crescimento equilibrado da economia independente da taxa de poupança. As modernas teorias do crescimento endógeno eliminam os retornos decrescentes e colocam retornos constantes para o fator acumulável, seja para capital físico (modelos AK), seja para o estoque de 'conhecimento' (Lucas). Como esse pressuposto geralmente não condiz com a realidade, não se pode [m] tomar os resultados das teorias como satisfatórios para a compreensão do objeto".

33. Formulação resultante de Bagchi (2006), Medeiros e Serrano (2001), Prebisch (2000, [1949]).

34. "England is distinctively the original home of Mercantilism" (Weber, 1950, p. 348).

35. Bagchi, 2006.

36. Chang, 2002.

37. Reis e Cardoso, 2009a, p. 356.

38. Idem.

39. Natal, 2006, p. 34.

\section{REFERÊNCIAS BIBLIOGRÁFICAS}

ARRIGHI, G. O longo século XX. Rio de Janeiro: Contraponto/ Unesp, 1995.

BAGCHI, A. The developmental state under imperialism. In: JOMO, K. S. (Ed.). Globalization under hegemony. [S.1.]: Oxford University Press, 2006.

BIELSCHOWSKY, R. (Ed.). Cinquenta anos de pensamento da Cepal. Rio de Janeiro: Record, v. 2, 2000.

CESARATTO, S.; SERRANO, F. As leis de rendimento nas teorias neoclássicas do crescimento: uma crítica sraffiana. Ensaios FEE, v. 23, n. 2, 2002.

CHANG, H. Chutando a escada: estratégias do desenvolvimento um uma perspectiva histórica. [S.1.]: Unesp, 2002.

Hamlet without the Prince of Denmark: How development has disappeared from today's 'development' discourse. In: KHAN S.; J. CHRISTIANSEN (Eds.). Towards New Developmentalism: Market as Means rather than Master. Abingdon: Routledge, 2009. 
CHESNAIS, F. A mundialização do capital. São Paulo: Xamã, 1996.

CHIBBER, V. (2005). Reviving the developmental state? The myth of the 'national bourgeoisie' in Socialist Register. Dutt, A. K. (2006) "International trade in early development economics”. In: JOMO, K. S.; REINERT, E. S. (Ed.). The origins of developmental economics. [S.1.]: Zed Books, [s.d.].

DUTT, A. K. International trade in early development economics. In: JOMO KS.; Reinert, E.S. (Ed.). The Origins of Development Economics. [S.1.] Zed Books, 2006.

ELIAS, N. O processo civilizador. Rio de Janeiro: Jorge Zahar Editores, 1993/1939.

FIORI, J. L. Globalização, hegemonia e império. In: FIORI, J. L. (Org.). Estados e moedas no desenvolvimento das nações. Petrópolis: Vozes, 1997.

De volta à questão da riqueza de algumas nações. In: FIORI, J. L. (Org.). Estados e moedas no desenvolvimento das nações. Petrópolis: Vozes, 1999.

Formação, expansão e limites do poder global. In: FIORI, J. L. (Org.). O Poder Americano. Petrópolis: Vozes, 2004.

O poder global e a nova geopolítica das nações. São Paulo: Boitempo, 2007a.

A nova geopolítica do sistema mundial no início do século XXI. In: Segundo Workshop Internacional do Projeto BRICS. Rio de Janeiro, abr. $2007 \mathrm{~b}$.

O sistema mundial, no início do século XX. In: FIORI, J. L.; MEDEIROS, C; SERRANO, F. O mito do colapso do poder americano. Rio de Janeiro: Record, 2008.

FRIEDMAN, T. O mundo é plano. Rio de Janeiro: Objetiva. 2005.

GILPIN, R. The Political Economy of the International Relations. Princenton: Princenton University Press, 1987.

KEOHANE, R.; NYE, J. S. Interdependence in world politics. In: CRANE, G. T.; AMAWI, A. (Ed.). The Theoretical Evolution of International Political Economy. Nova York: Oxford University Press. 1997.

KOTZ, D. M. The role of the state in economic transformation: comparing the transition experiences of Russia and China. [S.1.]: University of Massachusetts, out. 2004.

HILFERDING. O capital financeiro. São Paulo: Nova Cultural, 1985.

LEWIS, A. The Evolution of International Order. Londres: Allen \& Unwin, 1954.

MADDISON, A. Historical Statistics of the World Economy. In: http://www.ggdc.net/maddison/ 2006.

MANKIW, G. The Growth of Nations. Brookings Papers on Economic Activity, v. 1, p. 275-325, 1995.

MEDEIROS, C. A. Globalização e a inserção diferenciada da Ásia e da América Latina. In: TAVARES, M. C.; FIORI, J. L. Poder e dinheiro — uma economia política da globalização. Petrópolis: Vozes, 1997.

-; SERRANO, F. Inserção externa, exportações e crescimento no Brasil. In: FIORI, J. L.; MEDEIROS, C. A. (Ed.). Polarização mundial e crescimento. Rio de Janeiro: Vozes, 2001.

NATAL, J. Do desenvolvimentismo ao neoliberalismo - A saga brasileira no século XX. Rio de Janeiro: Pubblicati, 2006. Keohane, R.; Nye, J. (1997) Interdependence in world poli- 
tics. In: CRANE, G.; AMAWI, A. (Ed.). The Theoretical Evolution of International Political Economy. Nova York: Oxford University Press, [S.d.].

PALMA, G. Latin America during the second half of the twentieth century. In: CHANG, H. (Ed.). Rethinking Development Economics. [S.1.]: Anthem Press, 2003.

PAULANI, L. M. Neoliberalismo e retórica: o capítulo brasileiro. In: ENCONTRO NACIONAL DE ECONOMIA, 32. João Pessoa: PB, 2004.

POSSAS, M. A dinâmica da economia capitalista: uma abordagem teórica. São Paulo: Brasiliense. 1987.

PREBISCH, R. (1949) O desenvolvimento econômico latino-americano e alguns de seus principais problemas. In: BIELSCHOWSKY, R. (Ed.). Cinquenta anos de pensamento da CEPAL. Rio de Janeiro: Record, 2000, v. 1.

REIS, C. F. B. O investimento público no Brasil entre 1950 e 2006 e o desenvolvimento econômico. (Dissertação de mestrado não publicada). Orientador: Carlos Aguiar de Medeiros, UFRJ, 2008.

REIS, C. F. B.; CARDOSO, F. G. A crucialidade dos condicionantes internos: o desenvolvimento comparado das colônias temperadas inglesas entre 1850 e 1930. Revista Estudos Econômicos, v. 39, n. 2, p. 329-357, 2009a.

. Outra vez a crucialidade dos condicionantes internos: o contraste das trajetórias de desenvolvimento econômico de Brasil, Argentina e Canadá entre 1850 e 1930. Revista Economia, v. 10, n. 3, p. 635-664, 2009 b.

RODRIGUEZ, O. O Estruturalismo latino-americano. Rio de Janeiro: Civilização Brasileira, 2009.

SERRANO, F. Equilíbrio neoclássico de mercado de fatores: um ponto de vista Sraffiano. Ensaios FEE, v. 22, n. 1, 2001.

SOLOW, R. M. The Neoclassical Theory of Growth and Distribution. BNL Quarterly Review, v. 53, n. 215, 2000.

TILlY, C. Coerção, capital e estados europeus. São Paulo: Edusp, 1996.

WALLERSTEIN, I. World System Analysis. London: Duke University Press, 2004.

WEBER, M. General Economic History. Illinois: The Free Press, Glencoe, 1950/1920. 